\title{
Patient perspectives on antipsychotic treatments and their association with clinical outcomes
}

This article was published in the following Dove Press journal:

Patient Preference and Adherence

16 September 2010

Number of times this article has been viewed

\author{
Hong Liu-Seifert' \\ Olawale O Osuntokun' \\ Jenna L Godfrey ${ }^{2}$ \\ Peter D Feldman' \\ 'Lilly Research Laboratories, \\ Indianapolis, IN, USA; ${ }^{2}$ Durham \\ Veterans Affairs Medical Center, \\ Durham, NC, USA
}

Correspondence: Hong Liu-Seifert Lilly Research Laboratories, Lilly Corporate Center, Drop Code 6152, Indianapolis, IN 46285, USA

Tel +l 3174330662

Fax +I 3172766026

Email liu-seifert_hong@lilly.com

\begin{abstract}
This analysis examined patient-reported attitudes toward antipsychotic medication and the relationship of these attitudes with clinical outcomes and pharmacotherapy adherence. The analysis included three randomized, double-blind studies in patients with schizophrenia, schizoaffective disorder, or schizophreniform disorder diagnosed according to the Diagnostic and Statistical Manual of Mental Disorders 4th Edition and randomly assigned to treatment with olanzapine 5-20 mg/day or another antipsychotic (haloperidol 2-20 mg/day, risperidone 2-10 mg/day, or ziprasidone $80-160 \mathrm{mg}$ /day). Patient-reported improvements were significantly greater for olanzapine $(n=488)$ versus other treatments (haloperidol $n=145$, risperidone $n=158$, or ziprasidone $\mathrm{n}=271$ ) on multiple Drug Attitude Inventory items. A positive attitude toward medication reported by patients was significantly associated with greater clinical improvement on the Positive and Negative Syndrome Scale and lower discontinuation rates. These results suggest that patients' perceptions of treatment benefits are associated with objective clinical measures, including reduction of symptom severity and lower discontinuation rates. Furthermore, olanzapine may be associated with more positive treatment attitudes. These findings may contribute to a better understanding of reasons for treatment adherence from patients' own perspectives. Keywords: antipsychotic agents, medication adherence, patient satisfaction, schizophrenia, treatment efficacy
\end{abstract}

\section{Introduction}

Nonadherence to pharmacotherapy has long been recognized as a problem in the treatment of schizophrenia. Even the most conservative estimates indicate a discontinuation rate in naturalistic studies of approximately half of all patients within one year of their most recent episode. ${ }^{1,2}$ A 2008 analysis of Medicaid prescription records for 5898 patients with schizophrenia revealed that more than $90 \%$ of patients discontinued treatment within a year of filling their first (index) prescriptions. ${ }^{3}$ Nonadherence to treatment is associated with poorer clinical and functional outcomes, increased use of emergency psychiatric services, and an increased number of hospitalizations. ${ }^{4,5}$ In fact, noncompliance is the leading contributor to relapse, ${ }^{6,7}$ and the overwhelming majority of patients with schizophrenia who require hospitalization have generally been noncompliant in the period leading up to their most recent episode. ${ }^{6}$ Conversely, longer duration of treatment is associated with reduced rates of relapse and hospitalization. ${ }^{8}$

Numerous studies have found that type of medication may influence treatment nonadherence. In some studies, the use of atypical antipsychotics was seen to be associated with greater treatment adherence relative to conventional neuroleptics, ${ }^{9-11}$ It has been posited that the improved control over negative symptoms and the reduced 
risk of extrapyramidal symptoms during treatment with the atypical medications should confer greater adherence to treatment. ${ }^{12,13}$ Moreover, some research suggests that patients receiving atypical antipsychotics have more favorable subjective responses to their current medication than those receiving conventional medications. ${ }^{14-16}$ However, other studies report no difference or suggest patient characteristics may be responsible for differences in adherence rather than type of medication. ${ }^{17}$

The health belief model suggests that patient likelihood to continue with medication intake is a product of an implicit and subjective assessment of the relative risks and benefits of the medicine in relation to personal goals and constraints. $)^{18-20}$ In this model, patients are more likely to stay on treatment when they believe that their need for treatment and the benefits of treatment outweigh the negative aspects.

The potential association between patients' subjective attitudes toward medication and treatment adherence, as well as objective symptom responsiveness, has not been fully characterized and deserves greater research attention. To explore this relationship, this analysis examined differences in patients' attitudes toward treatment with olanzapine, haloperidol, risperidone, and ziprasidone, and how these attitudes might be related to differences in discontinuation rates and improvements in symptom severity.

\section{Methods}

\section{Studies}

This was a post hoc analysis of clinical trials within the Eli Lilly and Company olanzapine database. The selection criteria for the clinical trials included in this research were (1) randomized, double-blind, active comparator, (2) involving a minimum of 50 patients, and (3) having collected both the Positive and Negative Syndrome Scale (PANSS) ${ }^{21}$ and the Drug Attitude Inventory 10-item version (DAI-10). ${ }^{22}$ Three studies met these criteria and formed the basis of this analysis. All were large multicenter trials performing head-to-head comparisons of the safety and efficacy of olanzapine with another antipsychotic. Study 1 (F1D-MC-HGGN, completed before initiation of the Clinical Trial Registry) was conducted at 39 sites in the US and Canada, and compared the safety and efficacy of olanzapine, haloperidol, and risperidone. ${ }^{23}$ Study 2 (F1D-MC-HGHJ, Clinical Trial Registry \#NCT00036088) was conducted at 79 sites in North and South America and Europe, and compared olanzapine and ziprasidone. ${ }^{24}$ Study 3 (F1D-US-HGHO, completed before initiation of the Clinical Trial Registry) was conducted at 18 sites in the US, and compared olanzapine plus lorazepam with haloperidol plus lorazepam. ${ }^{25}$ Studies 1 and 2 were both long-term trials, with Study 1 conducted over 12 months and Study 2 conducted over 28 weeks. Study 3 was a short-term study conducted over three weeks.

\section{Patient sample}

Participating subjects were adult (18-65 years) male or female patients. In Study 1, participants were inpatients or outpatients who had met the diagnostic criteria for schizophrenia or schizoaffective disorder, as defined by the Diagnostic and Statistical Manual of Mental Disorders, 4th Edition (DSM-IV), ${ }^{26}$ and had a minimum baseline score of 4 on at least two items of the PANSS positive subscale and a minimum score of 18 (ie, individual item score range 0-6, total range 0-108) on the 18-item Brief Psychiatric Rating Scale (BPRS). ${ }^{27}$ In Study 2, participants were inpatients or outpatients who met the DSM-IV diagnostic criteria for schizophrenia and had a minimum score of 4 on the Clinical Global Impressions-Severity scale (CGI-S) ${ }^{28}$ and a baseline score of at least 42 (ie, individual item score range 1-7; total range 18-126) on the BPRS, with a score of 4 or more on at least one of the PANSS positive subscale items. In Study 3 , the sample consisted of acutely psychotic patients who were initially inpatients and who met the DSM-IV diagnostic criteria for schizophrenia, or schizophreniform or schizoaffective disorder. Patients had a minimum score of 20 on the PANSS agitation subscale (range 0-60) and a CGI-S score of at least 4 at baseline. Female patients of childbearing potential were required to be using a medically accepted means of contraception (for Study 3 only).

Patients with any acute, serious, or unstable medical conditions, including inadequately controlled diabetes, hepatic insufficiency, recent cerebrovascular accidents, uncontrolled seizure disorders, serious acute systemic infection, or immunologic disease, or unstable cardiovascular disorder were excluded. Also excluded were any patients who had undergone treatment with an injectable depot antipsychotic within one dosing interval before randomization. Before participation, patients or their legal representatives each received a complete description of their study and signed an informed consent document approved by the investigative site's institutional review board. All studies were conducted under the principles of the Declaration of Helsinki. ${ }^{29}$

\section{Treatments}

Each of the three studies included in this analysis was a randomized, double-blind, parallel trial comparing treatment 
with oral olanzapine with another orally administered atypical antipsychotic or haloperidol. Studies 1 and 2 began with a washout and placebo lead-in period lasting from two to nine days before treatment randomization. In Study 1, patients were randomly assigned to treatment with either olanzapine 5-20 mg/ day, haloperidol 2-19 mg/day, or risperidone 2-10 mg/day for up to 12 months, whereas in Study 2, patients were assigned to either olanzapine $10-20 \mathrm{mg} /$ day or ziprasidone $80-160 \mathrm{mg}$ / day (the latter administered in split, twice-daily doses) for up to 28 weeks. In Study 3, the washout period was applied for up to 24 hours, after which patients were assigned to either olanzapine $10-20 \mathrm{mg} /$ day plus lorazepam as needed for behavioral agitation, or haloperidol 10-20 mg/day plus lorazepam as needed, for up to three weeks. As the trial progressed, the use of adjunctive lorazepam was gradually restricted so that by the middle of the third week, patients were no longer receiving lorazepam.

\section{Assessments}

The PANSS is an assessment tool that measures the severity of psychiatric symptoms of psychosis. It consists of 30 items, each rated on a scale from $1=$ absent to $7=$ extreme, with totals ranging from 30 to 210 . In addition to the PANSS total score, this analysis examines changes in the five dimensions proposed by Davis and Chen, ${ }^{30}$ ie: depressive, which includes symptoms of anxiety (Items 15-17 and 20); disorganized thought (Items 12, 18, 19, 24, 25, and 27); hostility, which includes symptoms of excitement and impulsivity (Items 4 , 7,22 , and 28); negative, which includes negative symptoms (Items 8-11, 13, 21, and 30); and positive, which includes positive symptoms (Items 1-3, 5, 6, 14, 23, 26, and 29).

The DAI-10 is a 10-item, self-reported scale, extracted from the full 30 -item version of the DAI, ${ }^{22}$ that measures subjective feelings of patients with schizophrenia toward their current medications. The DAI-10 total score is the sum of Items 1 through 10, and individual items are scored as either " 0 ", which means "no" or "1", which means "yes" based on whether the patient agrees with the statement. Items 1, 3, 4, 7, 9, and 10 reflect positive attitudes toward the current medication, while items 2, 5, 6, and 8 reflect negative attitudes.

\section{Analyses}

Separate comparisons between treatments were made in a head-to-head fashion between olanzapine and each of the three active comparators in turn, in order to allow for fair comparisons of each pair of drugs based on the same studies. Data for head-to-head comparison of olanzapine and risperidone were obtained from Study 1, while data for comparison of olanzapine and ziprasidone were obtained from Study 2.
Data for comparison of olanzapine and haloperidol were pooled from Studies 1 and 3 .

Baseline treatment differences for categoric variables (eg, demographics and diagnostic categories) were analyzed via Fisher's exact test, while continuous variables (eg, age and PANSS) were analyzed by analysis of variance with term for treatment. Treatment differences in rates of endpoint responses (ie, agreement or disagreement) with DAI-10 items were analyzed using Fisher's exact test. To explore potential associations between differences in attitude to treatment on the one hand and differences in completion rates or PANSS scores on the other, completion rates and PANSS subscale scores were compared between patients responding with agreement to each DAI-10 item and those responding with disagreement, using Fisher's exact test to compare completion rates and analysis of variance (last observation carried forward) to compare PANSS scores. All tests in this report are based on a two-tailed $\alpha$ significance of 0.05 .

\section{Results}

\section{Patient demographics and baseline characteristics}

A total of 1221 patients were represented in these analyses (Table 1), roughly evenly randomized to treatment with either olanzapine $(n=647)$ or one of the other antipsychotics (all other antipsychotics $n=574$ [haloperidol $n=145$, risperidone $\mathrm{n}=158$, ziprasidone $\mathrm{n}=271 \mathrm{]})$. The majority of patients were male $(68.2 \%)$, and most had received a diagnosis of schizophrenia $(81.8 \%)$, with smaller numbers receiving diagnoses of schizoaffective disorder $(18.0 \%)$ or schizophreniform disorder $(0.2 \%)$. Racially or ethnically, the sample was composed primarily of patients of Caucasian (51.4\%) origin, with lower proportions identifying themselves as of African origin (28.2\%), Hispanic ethnicity (13.8\%), East Asian (1.4\%), West Asian $(0.4 \%)$, or "other" $(4.8 \%)$. The mean age in all three studies was in the late $30 \mathrm{~s}$, with a mean age at onset of illness in the early 20s. Baseline PANSS total scores indicated a mean illness severity in the moderate range. No significant difference was seen in any demographic characteristic between patients assigned to olanzapine treatment and those assigned to any other antipsychotic agent (Table 1).

\section{Mean change in PANSS total and subscale scores from baseline to endpoint}

When compared with patients treated with haloperidol, patients treated with olanzapine had significantly greater improvement on the PANSS total score $(P=0.011)$, as well 
Table I Patient demographics and baseline characteristics

\begin{tabular}{|c|c|c|c|c|c|c|c|c|c|}
\hline \multirow[t]{2}{*}{ Measure } & \multicolumn{3}{|c|}{ Olanzapine versus haloperidol } & \multicolumn{3}{|c|}{ Olanzapine versus risperidone } & \multicolumn{3}{|c|}{ Olanzapine versus ziprasidone } \\
\hline & $\begin{array}{l}\text { Olanzapine } \\
(n=2 I I)\end{array}$ & $\begin{array}{l}\text { Haloperidol } \\
(n=145)\end{array}$ & $P$ value & $\begin{array}{l}\text { Olanzapine } \\
(n=159)\end{array}$ & $\begin{array}{l}\text { Risperidone } \\
(n=158)\end{array}$ & $P$ value & $\begin{array}{l}\text { Olanzapine } \\
(n=277)\end{array}$ & $\begin{array}{l}\text { Ziprasidone } \\
(n=27 I)\end{array}$ & $P$ value \\
\hline $\begin{array}{l}\text { Age, years, } \\
\text { mean (SD) }\end{array}$ & $38.6(8.4)$ & $39.7(8.6)$ & 0.20 & $38.4(7.9)$ & $39.5(8.3)$ & 0.23 & $40.1(11.6)$ & $38.2(12.1)$ & 0.07 \\
\hline $\begin{array}{l}\text { Age at onset, } \\
\text { mean (SD) }\end{array}$ & $22.6(6.9)$ & $22.0(7.2)$ & 0.41 & $23.0(7.0)$ & $23.3(7.2)$ & 0.72 & $23.9(8.3)$ & $22.8(8.2)$ & 0.11 \\
\hline Males, \% & 72.0 & 71.0 & 0.90 & 72.3 & 70.2 & 0.71 & 65.0 & 63.5 & 0.72 \\
\hline $\begin{array}{l}\text { Racial/ethnic } \\
\text { origin, } n(\%)\end{array}$ & & & 0.27 & & & 0.31 & & & 0.77 \\
\hline African & $62(29.4)$ & $52(35.9)$ & & $43(27.0)$ & $43(27.2)$ & & $78(28.2)$ & $66(24.4)$ & \\
\hline Caucasian & |2| (57.3) & $71(49.0)$ & & $95(59.7)$ & I0I (63.9) & & II 5 (4I.5) & $124(45.8)$ & \\
\hline East Asian & $5(2.4)$ & $2(1.4)$ & & $3(1.9)$ & $2(1.3)$ & & $2(0.7)$ & $3(1.1)$ & \\
\hline Hispanic & $15(7.1)$ & II (7.6) & & $13(8.2)$ & $6(3.8)$ & & $63(22.7)$ & $61(22.5)$ & \\
\hline South Asian & $2(1.0)$ & $0(0.0)$ & & $2(1.3)$ & $0(0.0)$ & & I $(0.4)$ & $0(0.0)$ & \\
\hline Other & $6(2.8)$ & $9(6.2)$ & & $3(1.9)$ & $6(3.8)$ & & $18(6.5)$ & $17(6.3)$ & \\
\hline Diagnosis, n (\%) & & & 0.96 & & & 0.14 & & & - \\
\hline Schizophrenia & $135(64.0)$ & $94(64.8)$ & & $105(66.0)$ & II (74.0) & & $277(100.0)$ & $271(100.0)$ & \\
\hline Schizoaffective & $75(35.6)$ & $50(34.5)$ & & $54(34.0)$ & $4 \mathrm{I}(26.0)$ & & $0(0.0)$ & $0(0.0)$ & \\
\hline Schizophreniform & I (0.5) & I (0.7) & & $0(0.0)$ & $0(0.0)$ & & $0(0.0)$ & $0(0.0)$ & \\
\hline $\begin{array}{l}\text { Baseline PANSS } \\
\text { total, mean (SD) }\end{array}$ & $87.2(16.5)$ & $88.5(17.6)$ & 0.47 & $82.6(13.1)$ & $84.2(14.7)$ & 0.32 & $99.8(19.1)$ & $102.0(21.2)$ & 0.19 \\
\hline $\begin{array}{l}\text { Mean modal dose } \\
(\mathrm{mg} / \text { day), mean }\end{array}$ & 14.0 & 16.4 & - & 12.3 & 5.2 & - & 15.3 & 116.0 & - \\
\hline
\end{tabular}

Abbreviations: PANSS, Positive and Negative Syndrome Scale; SD, standard deviation.

as the depressive $(P=0.012)$ and disorganized thought $(P=0.025)$ subscale scores at endpoint. In comparison with patients treated with risperidone, patients treated with olanzapine has significantly greater improvements on the disorganized thought subscale at endpoint $(P=0.011)$. Lastly, olanzapine treatment was associated with significantly greater improvements on the PANSS total score, as well as the depressive, disorganized thoughts, hostility, negative, and positive subscale scores at endpoint when compared with patients treated with ziprasidone (all $P<0.001$, Table 2 ).

\section{Comparison of patient attitudes to treatment: DAI- I0 scores}

Olanzapine treatment was associated with higher percentages of patients reporting a positive attitude on the majority of DAI-10 items relative to the other three medications (Table 3). These differences reached statistical significance for six items in the comparisons with haloperidol (Items 1, $2,4,5,7$, and 9), two items in the comparisons with risperidone (Items 1 and 4), and one item in the comparisons with ziprasidone (Item 2).

\section{Patient attitudes and adherence}

When pooled across antipsychotic medications, patients with a positive attitude toward their medication had a significantly greater likelihood of completing their treatment (see Figure 1). On every item of the DAI-10, patients reporting a positive attitude toward treatment had significantly higher completion rates than did those reporting a negative attitude. Differences were the greatest for items 1 (positive response = agreement

Table 2 Changes in Positive and Negative Syndrome Scale total and subscale scores at endpoint, by treatment

\begin{tabular}{|c|c|c|c|c|c|c|c|c|c|}
\hline \multirow[t]{2}{*}{ PANSS scale } & \multicolumn{3}{|c|}{ Olanzapine versus haloperidol } & \multicolumn{3}{|c|}{ Olanzapine versus risperidone } & \multicolumn{3}{|c|}{ Olanzapine versus ziprasidone } \\
\hline & Olz & Hal & $P$ value & Olz & Ris & $P$ value & Olz & Zip & $P$ value \\
\hline Total & -16.7 & -12.6 & 0.011 & -12.4 & -9.5 & 0.054 & -35.7 & -26.0 & $<0.001$ \\
\hline Depressive & -2.3 & -1.7 & 0.012 & -2.0 & -1.6 & 0.18 & -3.9 & -3.0 & $<0.001$ \\
\hline $\begin{array}{l}\text { Disorganized } \\
\text { thought }\end{array}$ & -2.8 & -2.1 & 0.025 & -1.9 & -1.3 & 0.011 & -6.0 & -4.1 & $<0.001$ \\
\hline Hostility & -2.0 & -1.8 & 0.26 & -0.9 & -0.6 & 0.54 & -4.2 & -2.6 & $<0.001$ \\
\hline Negative & -3.1 & -2.1 & 0.07 & -2.6 & -1.8 & 0.10 & -8.4 & -6.7 & $<0.001$ \\
\hline Positive & -6.4 & -5.1 & 0.08 & -5.1 & -4.2 & 0.19 & -13.2 & -9.6 & $<0.001$ \\
\hline
\end{tabular}

Abbreviations: Hal, haloperidol; Olz, olanzapine; PANSS, Positive and Negative Syndrome Scale; Ris, risperidone; Zip, ziprasidone. 
Table 3 Drug Attitude Inventory items, percent agreeing at endpoint, by treatment

\begin{tabular}{|c|c|c|c|c|c|c|c|c|c|}
\hline \multirow[t]{2}{*}{ DAl item } & \multicolumn{3}{|c|}{$\begin{array}{l}\text { Olanzapine versus } \\
\text { haloperidol }\end{array}$} & \multicolumn{3}{|c|}{$\begin{array}{l}\text { Olanzapine versus } \\
\text { risperidone }\end{array}$} & \multicolumn{3}{|c|}{$\begin{array}{l}\text { Olanzapine versus } \\
\text { ziprasidone }\end{array}$} \\
\hline & Olz & Hal & $P$ value & Olz & Ris & $P$ value & Olz & Zip & $P$ value \\
\hline 0I: Good outweighs bad & 86.3 & 75.8 & 0.022 & 84.4 & 73.7 & 0.036 & 86.5 & 82.4 & 0.26 \\
\hline 02: Feel weird, like a "zombie" & 17.9 & 35.0 & 0.001 & 17.0 & 20.3 & 0.53 & 18.0 & 25.8 & 0.037 \\
\hline 03: Take meds of own free choice & 88.6 & 86.9 & 0.72 & 87.4 & 84.2 & 0.49 & 84.1 & 80.4 & 0.34 \\
\hline 04: Feel more relaxed & 84.8 & 68.0 & 0.001 & 85.2 & 75.2 & 0.046 & 79.2 & 76.3 & 0.45 \\
\hline 05: Feel tired/sluggish & 37.5 & 50.8 & 0.025 & 37.0 & 39.8 & 0.71 & 30.7 & 35.8 & 0.25 \\
\hline 06: Take meds only when sick & 59.2 & 53.7 & 0.35 & 64.4 & 66.9 & 0.70 & 35.5 & 31.4 & 0.39 \\
\hline 07: Feel more normal & 83.5 & 64.8 & $<0.001$ & 83.7 & 75.9 & 0.13 & 74.3 & 72.5 & 0.68 \\
\hline $\begin{array}{l}\text { 08: Unnatural to be controlled } \\
\text { by meds }\end{array}$ & 39.1 & 39.2 & $>0.99$ & 34.1 & 37.6 & 0.61 & 38.4 & 37.9 & 0.93 \\
\hline 09: Clearer thoughts & 81.0 & 66.9 & 0.007 & 81.5 & 78.9 & 0.65 & 74.3 & 77.1 & 0.53 \\
\hline 10: Med prevents sickness & 85.9 & 77.0 & 0.07 & 85.9 & 78.2 & 0.11 & 81.6 & 82.1 & 0.91 \\
\hline
\end{tabular}

Abbreviations: DAI, Drug Attitude Inventory; Hal, haloperidol; Olz, olanzapine; Ris, risperidone; Zip, ziprasidone.

with "For me, the good things about my current medication outweigh the bad") and 10 (positive response = agreement with "By staying on my medication, I can prevent getting sick"), and lowest - yet still significantly higher for positive attitudes - on items 8 (positive response $=$ disagreement with "It is unnatural for my mind and body to be controlled by medications") and 3 (positive response = agreement with "I take my medications of my own free choice").

\section{Patient attitudes and symptom control}

Across the antipsychotic medications, favorable attitudes toward current treatment were also associated with improvements in symptom severity, as shown by greater reductions in PANSS subscale scores associated with positive attitudes on the individual items of the DAI-10 (Table 4). However, no specific symptom clusters reflected patients' attitudes to a greater or lesser degree, and all five subscales showed significantly greater score reductions among patients reporting positive attitudes than those reporting negative attitudes for most of the items of the DAI-10. Most items of the DAI-10 showed a significant correlation with all five PANSS dimensions. However, there was essentially no correlation between attitude toward treatment and symptom reduction for DAI-10 item 8, "It is unnatural for my mind and body to

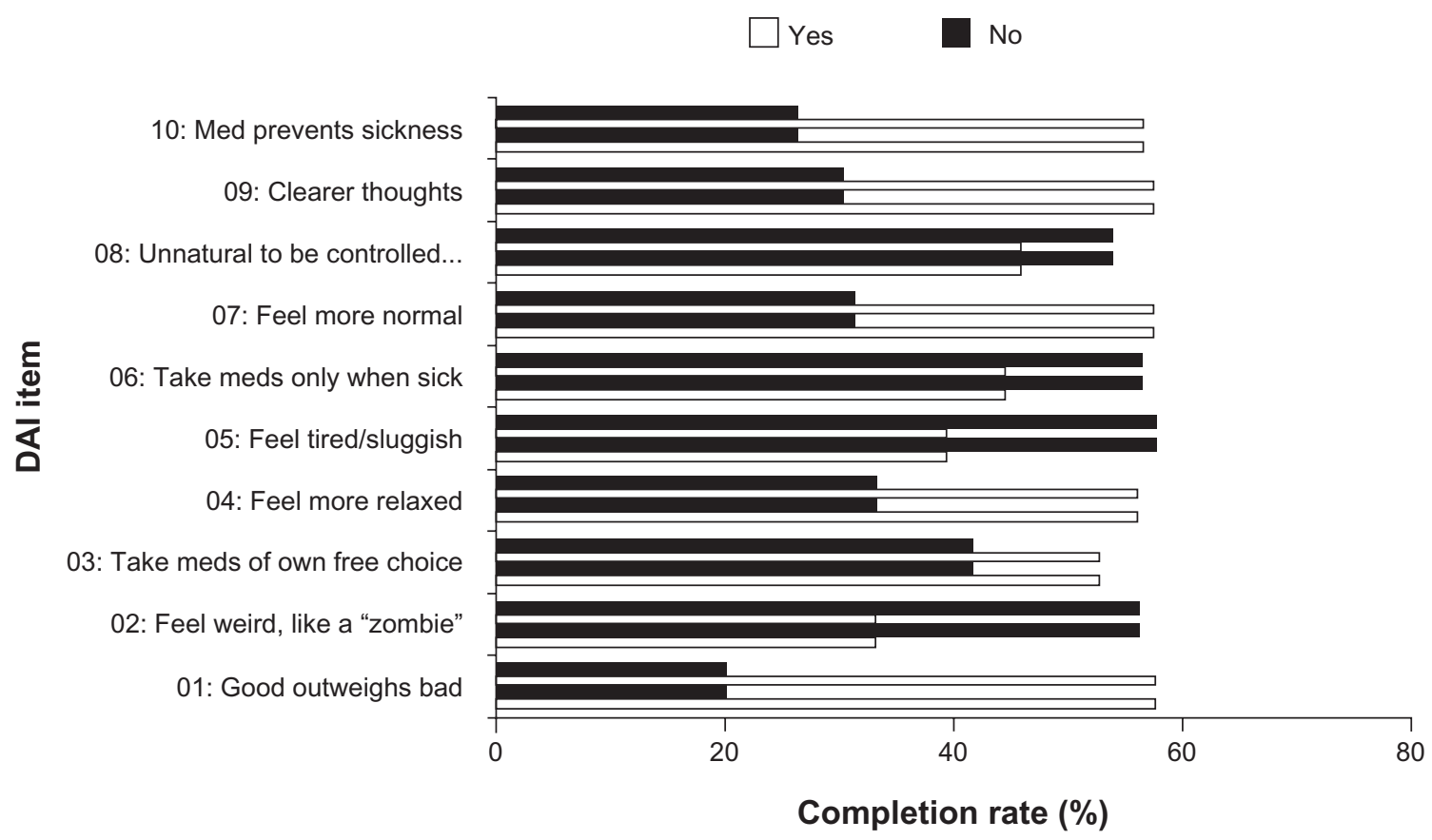

Figure I Completion rates, by endpoint Drug Attitude Inventory response for all patients. Patients with a positive attitude toward their medication had a greater likelihood of completing their treatment $(* P<0.05 ; * * * P<0.001)$. 


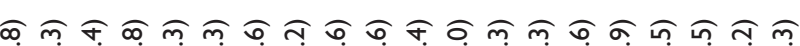

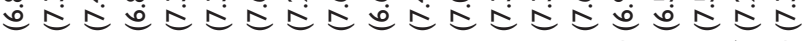

ํㅏ

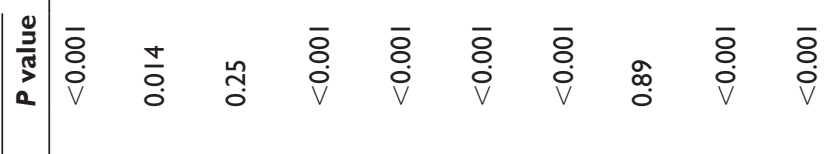

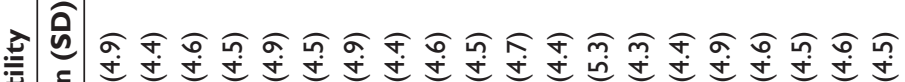

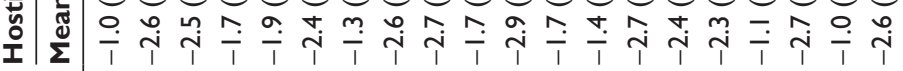

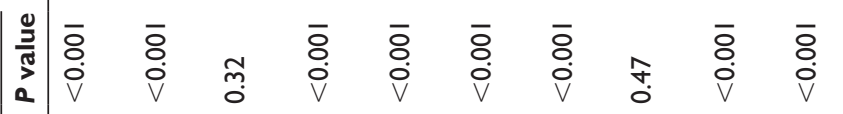

ثُ

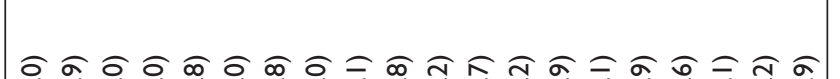

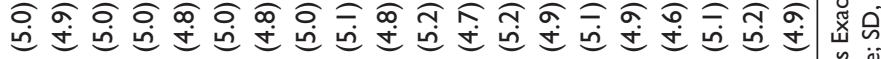

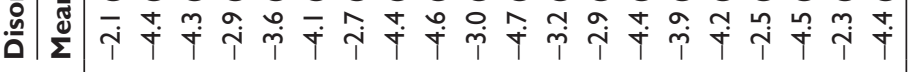

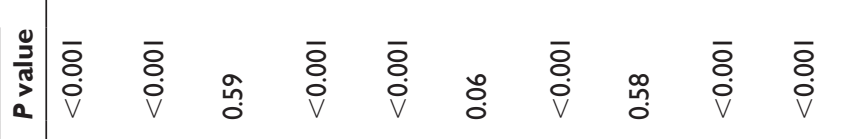

อิ 广户்

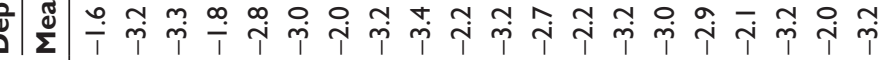

z ㅎํ

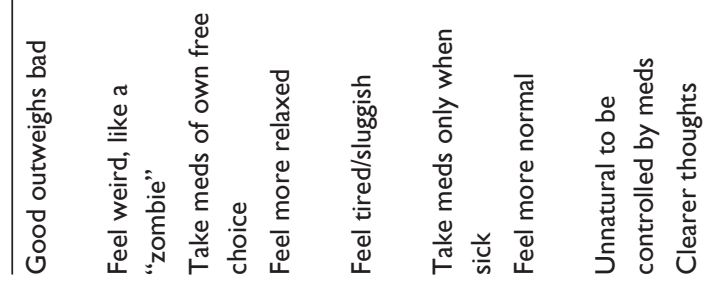


be controlled by medications", which showed no significant differences in PANSS score reductions between patients with positive versus negative attitudes for any PANSS subscale. The correlation was likewise weak for item 3, "I take my medications of my own free choice", which showed a significant difference for just the PANSS negative subscale.

\section{Discussion}

The principal findings from these analyses demonstrate that treatment with olanzapine may be associated with better medication perceptions than those for haloperidol, risperidone, or ziprasidone. Furthermore, patient subjective attitude toward medication is associated with treatment adherence and objective measures of symptom responsiveness among patients with schizophrenia. Positive attitude toward medication, as measured by DAI-10, was shown to be associated with significantly higher study completion rates and greater symptom reduction in all five dimensions of the PANSS.

No particular symptom dimension appeared to have a higher or lower association than any other with medication attitude. This was unexpected, because numerous studies have identified positive symptom severity as the leading predictor of higher risk of discontinuation. ${ }^{31-35}$ Moreover, patient compliance ${ }^{36,37}$ and attitude toward medication ${ }^{15}$ have been linked to PANSS positive subscale scores. However, the depressive symptom cluster has also been implicated as an important factor in both adherence ${ }^{5,32,35}$ and attitude toward medication, ${ }^{38}$ as have symptoms of hostility/excitement. ${ }^{5,39}$ In fact, recently published data ${ }^{16}$ show that, while the positive symptom cluster may indeed be the strongest predictor of patient attitudes and adherence, a correlation can nevertheless be found between adherence and general PANSS symptom reduction. Although this study did not explicitly examine the association between discontinuation and symptom severity within specific symptomatic dimensions, the two do appear to have a strong relationship. ${ }^{30,40-42}$ This, however, has the potential to be complicated by other factors, such as dosing frequency ${ }^{17,43}$ and patients' levels of insight. ${ }^{38,43-45}$

In this research, symptom severity, adherence to treatment, and attitudes toward medication were examined simultaneously. Clearly there is a complex interaction between these and other aspects of schizophrenia and its treatment, such as a medication's tolerability and adverse event profile, patients' insight into their own condition, and perceived social pressures from the stigma associated with having the disease, or indeed of taking medication for its alleviation. Studies involving the conventional antipsychotics had earlier implicated the incidence of akathisia as a major determinant of treatment discontinuation. ${ }^{17,46}$ However, with the increased use of the second-generation, atypical antipsychotics, akathisia has become less of an issue, ${ }^{9,47}$ and indeed current thinking is that lack of efficacy, rather than tolerability profile, is a stronger predictor of early discontinuation. ${ }^{7,35,48-50}$ Medication noncompliance and undercompliance continue to be a problem in the treatment of schizophrenia; the vast majority of hospital admissions for exacerbation of psychosis have been linked to noncompliance, ${ }^{6,51}$ which may still be the most important militating factor in relapse. ${ }^{6}$

The correlations between patient attitude toward medication, treatment persistence, and symptom improvement in the present research do not suggest a causal relationship. Possibly the positive attitude toward medication has contributed to patients staying on treatment longer. It is also possible that longer treatment duration helped patients to gain better insight, and thus a better perception of the medication. Similarly, positive patient attitude and behavior may have contributed to improved psychopathology. Conversely, improvement in symptoms and the recognition of this improvement by patients may have led to improvement in their attitude to medication.

A potential limitation of the present analysis is that all-cause discontinuation was used to measure treatment persistence. In keeping with the objectives of the Clinical Antipsychotic Trials of Intervention Effectiveness (CATIE) studies, ${ }^{42,52}$ all-cause discontinuation of treatment had been selected for the current set of analyses because it integrates patients' and clinicians' assessments of efficacy and tolerability into a single global measure that reflects a medication's balance of relative benefits and risks. Other limitations that warrant mention include the differences in baseline PANSS scores and study designs among the source studies, which may have been mitigated to some extent by the use of withinstudy comparisons and the limited sample sizes. Finally, it should be pointed out that the data were all derived from clinical trials under controlled conditions and with attendant exclusion and inclusion criteria, and therefore the results may not be easily extrapolated to the entire population of patients with schizophrenia.

In summary, the results of this post hoc analysis indicate that patients' subjective perceptions of treatment benefits may be associated with objective clinical measures, including reduction of symptom severity and lower discontinuation rates. These findings may contribute to a better understanding of the patient's own perspective of antipsychotic treatment and its implications for treatment adherence. 


\section{Disclosure}

This work was sponsored by Eli Lilly and Company. Drs LiuSeifert, Osuntokun, and Feldman are employees and shareholders of Eli Lilly and Company. Ms Godfrey is a former visiting scientist at Eli Lilly and Company. Appreciation is expressed to Angela C Lorio of i3/Statprobe, Inc., for editorial assistance with the manuscript. Ms Lorio has no conflicts of interest to report.

\section{References}

1. Gaebel W, Pietzcker A. One-year outcome of schizophrenic patients the interaction of chronicity and neuroleptic treatment. Pharmacopsychiatry. 1985;18:235-239.

2. Novak-Grubic V, Tavcar R. Predictors of noncompliance in males with first-episode schizophrenia, schizophreniform and schizoaffective disorder. Eur Psychiatry. 2002;17:148-154.

3. Mullins CD, Obeidat NA, Cuffel BJ, Naradzay J, Loebel AD. Risk of discontinuation of atypical antipsychotic agents in the treatment of schizophrenia. Schizophr Res. 2008;98:8-15.

4. Ascher-Svanum H, Faries DE, Zhu B, Ernst FR, Swartz MS, Swanson JW. Medication adherence and long-term functional outcomes in the treatment of schizophrenia in usual care. J Clin Psychiatry. 2006;67:453-460.

5. Lindenmayer JP, Liu-Seifert H, Kulkarni PM, et al. Medication nonadherence and treatment outcome in patients with schizophrenia or schizoaffective disorder with suboptimal prior response. J Clin Psychiatry. 2009;70:990-996.

6. Ayuso-Gutiérrez JL, del Río Vega JM. Factors influencing relapse in the long-term course of schizophrenia. Schizophr Res. 1997;28:199-206.

7. Lindström E, Bingefors K. Patient compliance with drug therapy in schizophrenia. Economic and clinical issues. Pharmacoeconomics. 2000;18:106-124.

8. Weiden PJ, Kozma C, Grogg A, Locklear J. Partial compliance and risk of rehospitalization among California Medicaid patients with schizophrenia. Psychiatr Serv. 2004;55:886-891.

9. Janssen B, Gaebel W, Haerter M, Komaharadi F, Lindel B, Weinmann S. Evaluation of factors influencing medication compliance in inpatient treatment of psychotic disorders. Psychopharmacology. 2006;187:229-236.

10. Olfson M, Mechanic D, Hansell S, Boyer CA, Walkup J, Weiden PJ. Predicting medication noncompliance after hospital discharge among patients with schizophrenia. Psychiatr Serv. 2000;51:216-222.

11. Voruganti L, Cortese L, Owyeumi L, et al. Switching from conventional to novel antipsychotic drugs: Results of a prospective naturalistic study. Schizophr Res. 2002;57:201-208.

12. Bradford DW, Perkins DO, Lieberman JA. Pharmacological management of first-episode schizophrenia and related nonaffective psychoses. Drugs. 2003;63:2265-2283.

13. Thomas P, Alptekin K, Gheorghe M, Mauri M, Olivares JM, Riedel M. Management of patients presenting with acute psychotic episodes of schizophrenia. CNS Drugs. 2009;23:193-212.

14. Pollice R, Tomassini A, Malavolta M, et al. Subjective and psychopathological response in patients under different antipsychotic treatments: Are there differences in real clinical practice? J Biol Regul Homeost Agents. 2008;22:83-91.

15. Rocca P, Crivelli B, Marino F, Mongini T, Portaleone F, Bogetto F. Correlations of attitudes toward antipsychotic drugs with insight and objective psychopathology in schizophrenia. Compr Psychiatry. 2008;49:170-176.

16. Schennach-Wolff R, Jäger M, Seemuller F, et al. Attitude towards adherence in patients with schizophrenia at discharge. J Psychiatr Res. 2009;43:1294-1301.

17. Diaz E, Neuse E, Sullivan MC, Pearsall HR, Woods SW. Adherence to conventional and atypical antipsychotics after hospital discharge. J Clin Psychiatry. 2004;65:354-360.
18. Becker MH, Maiman LA. Sociobehavioral determinants of compliance with health and medical care recommendations. Med Care. 1975;13:10-24.

19. Fenton WS, Blyler CR, Heinssen RK. Determinants of medication compliance in schizophrenia: empirical and clinical findings. Schizophr Bull. 1997;23:637-651.

20. Perkins DO. Adherence to antipsychotic medications. J Clin Psychiatry. 1999;60:25-30.

21. Kay SR, Fiszbein A, Opler LA. The positive and negative syndrome scale (PANSS) for schizophrenia. Schizophr Bull. 1987;13:261-276.

22. Hogan TP, Awad AG, Eastwood R. A self-report scale predictive of drug compliance in schizophrenics: Reliability and discriminative validity. Psychol Med. 1983;13:177-183.

23. Keefe RSE, Young CA, Rock SL, Purdon SE, Gold JM, Breier A; the HGGN Study Group, 2006. One-year double-blind study of the neurocognitive efficacy of olanzapine, risperidone, and haloperidol in schizophrenia. Schizophr Res. 2006;81:1-15.

24. Breier A, Berg PH, Thakore JH, et al. Olanzapine versus ziprasidone: Results of a 28-week double-blind study in patients with schizophrenia. Am J Psychiatry. 2005;162:1879-1887.

25. Kinon BJ, Ahl J, Rotelli MD, McMullen E. Efficacy of accelerated dose titration of olanzapine with adjunctive lorazepam to treat acute agitation in schizophrenia. Am J Emerg Med. 2004;22:181-186.

26. American Psychiatric Association. Diagnostic and Statistical Manual of Mental Disorders, 4th Edition. Washington, DC: American Psychiatric Association; 1994.

27. Overall JE, Gorham DR. The Brief Psychiatric Rating Scale. Psychol Rep. 1962;10:799-812.

28. Guy W. ECDEU Assessment Manual for Psychopharmacology, Revised. Publication ADM 76-338. Bethesda, MD: United States Department of Health, Education, and Welfare; 1976.

29. World Medical Association, 2000. Declaration of Helsinki: Recommendations Guiding Medical Doctors in Biomedical Research Involving Human Subjects. As adopted by the 18th General Assembly; Helsinki, Finland; Jun 1964; and amended by the 52nd General Assembly; Edinburgh, Scotland; Oct 2000.

30. Davis JM, Chen N. The effects of olanzapine on the 5 dimensions of schizophrenia derived by factor analysis: Combined results of the North American and international trials. J Clin Psychiatry. 2001;62:757-771.

31. Haro JM, Novick D, Suarez D, Roca M. Antipsychotic treatment discontinuation in previously untreated patients with schizophrenia: 36-month results from the SOHO study. J Psychiatr Res. 2009;43:265-273.

32. Kinon BJ, Ascher-Svanum H, Adams DH, Chen L. The temporal relationship between symptom change and treatment discontinuation in a pooled analysis of 4 schizophrenia trials. J Clin Psychopharmacol. 2008;28:544-549.

33. Kupper Z, Tschacher W. Lack of concordance between subjective improvement and symptom change in psychotic episodes. Br J Clin Psychol. 2008;47:75-93.

34. Liu-Seifert H, Houston JP, Adams DH, Kinon BJ. Association of acute symptoms and compliance attitude in noncompliant patients with schizophrenia. J Clin Psychopharmacol. 2007;27: 392-394.

35. Perkins DO, Johnson JL, Hamer RM, et al; HGDH Research Group. Predictors of antipsychotic medication adherence in patients recovering from a first psychotic episode. Schizophr Res. 2006;83:53-63.

36. Karow A, Czekalla J, Dittmann RW, et al. Association of subjective well-being, symptoms, and side effects with compliance after 12 months of treatment in schizophrenia. J Clin Psychiatry. 2007;68:75-80.

37. Stankovic' Z, Britvic D, Vukovic O, Ille T. Treatment compliance of outpatients with schizophrenia: Patient's attitudes, demographic, clinical and therapeutic variables. Psychiatr Danub. 2008;20:42-52.

38. Mohamed S, Rosenheck R, McEvoy J, Swartz M, Stroup S, Lieberman JA. Cross-sectional and longitudinal relationships between insight and attitudes toward medication and clinical outcomes in chronic schizophrenia. Schizophr Bull. 2009;35:336-346. 
39. Gharabawi GM, Greenspan A, Rupnow MFT, et al. Reduction in psychotic symptoms as a predictor of patient satisfaction with antipsychotic medication in schizophrenia: Data from a randomized doubleblind trial. BMC Psychiatry. 2006;6:45.

40. Fleischhacker WW, McQuade RD, Marcus RN, Archibald D, Swanink R, Carson WH. A double-blind, randomized comparative study of aripiprazole and olanzapine in patients with schizophrenia. Biol Psychiatry. 2009;65:510-517.

41. Kinon BJ, Lipkovich I, Edwards SB, Adams DH, Ascher-Svanum H, Siris SG. A 24-week randomized study of olanzapine versus ziprasidone in the treatment of schizophrenia or schizoaffective disorder in patients with prominent depressive symptoms. J Clin Psychopharmacol. 2006;26:157-162.

42. Stroup TS, Lieberman JA, McEvoy JP, et al; for the CATIE Investigators Effectiveness of olanzapine, quetiapine, risperidone, and ziprasidone in patients with chronic schizophrenia following discontinuation of a previous atypical antipsychotic. Am J Psychiatry. 2006;163:611-622.

43. Burton SC. Strategies for improving adherence to second-generation antipsychotics in patients with schizophrenia by increasing ease of use. J Psychiatr Pract. 2005;11:369-378.

44. Byerly MJ, Fisher R, Carmody T, Rush AJ. A trial of compliance therapy in outpatients with schizophrenia or schizoaffective disorder. J Clin Psychiatry. 2005;66:997-1001.

45. Patel MX, de Zoysa N, David AS. A cross-sectional study of patients' perspectives on adherence to antipsychotic medication: Depot versus oral. J Clin Psychiatry. 2008;69:1548-1556.
46. van Putten T. Why do schizophrenic patients refuse to take their drugs? Arch Gen Psychiatry. 1974;31:67-72.

47. Awad AG, Voruganti LNP. New antipsychotics, compliance, quality of life, and subjective tolerability - are patients better off? Can J Psychiatry. 2004;49:297-302.

48. Kinon BJ, Liu-Seifert H, Adams DH, Citrome L. Differential rates of treatment discontinuation in clinical trials as a measure of treatment effectiveness for olanzapine and comparator atypical antipsychotics for schizophrenia. J Clin Psychopharmacol. 2006;26:632-637.

49. Kinon BJ, Noordsy DL, Liu-Seifert H, Gulliver AH, Ascher-Svanum H, Kollack-Walker S. Randomized, double-blind 6-month comparison of olanzapine and quetiapine in patients with schizophrenia or schizoaffective disorder with prominent negative symptoms and poor functioning. J Clin Psychopharmacol. 2006;26:453-461.

50. Liu-Seifert H, Adams DH, Kinon BJ. Discontinuation of treatment of schizophrenic patients is driven by poor symptom response: A pooled post-hoc analysis of four atypical antipsychotic drugs. BMC Med. 2005;3:21

51. Masand PS, Narasimhan M. Improving adherence to antipsychotic pharmacotherapy. Curr Clin Pharmacol. 2006;1:47-56.

52. Lieberman JA, Stroup TS, McEvoy JP, et al; for the Clinical Antipsychotic Trials of Intervention Effectiveness (CATIE) Investigators. Effectiveness of antipsychotic drugs in patients with chronic schizophrenia. N Engl J Med. 2005;353:1209-1223.
Patient Preference and Adherence

\section{Publish your work in this journal}

Patient Preference and Adherence is an international, peer-reviewed, open access journal focusing on the growing importance of patient preference and adherence throughout the therapeutic continuum. Patient satisfaction, acceptability, quality of life, compliance, persistence and their role in developing new therapeutic modalities and compounds to

\section{Dovepress}

optimize clinical outcomes for existing disease states are major areas of interest. This journal has been accepted for indexing on PubMed Central. The manuscript management system is completely online and includes a very quick and fair peer-review system. Visit http://www.dovepress.com/ testimonials.php to read real quotes from published authors. 